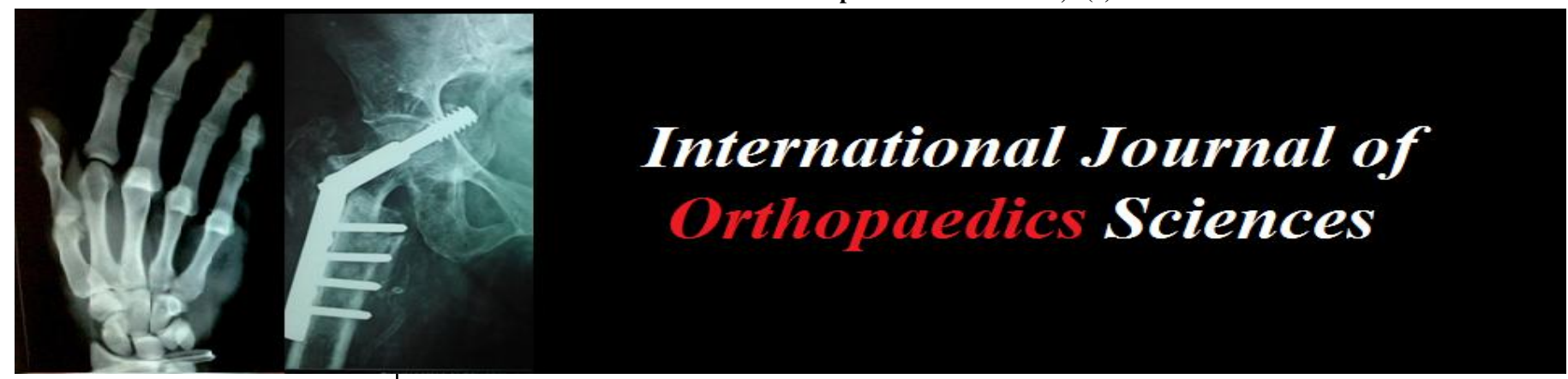

ISSN: $2395-1958$

IJOS 2017; 3(2): 801-805

(C) 2017 IJOS

www.orthopaper.com

Received: 26-02-2017

Accepted: 27-03-2017

Dr. Mahesh Babu

MBBS MS (Ortho), Assistant

Professor, Chengelpet Medical

College, G.S.T. Road,

Kancheepuram, Chengalpattu,

Tamil Nadu, India

Dr. Vijay Anand

MBBS MS (Ortho), Associate

Professor, SRM Medical College,

SRM Nagar, Potheri,

Kattankulathur, Kancheepuram

District, Near Potheri Railway

Station, Chennai, Tamil Nadu,

India

Dr. Sriram Thanigai

MBBS MS (Ortho), Professor,

SRM medical college, SRM

Nagar, Potheri, Kattankulathur,

Kancheepuram District, Near

Potheri Railway Station,

Chennai, Tamil Nadu, India

\section{Results of modified Carroll technique in severe, resistant clubfeet}

\section{Dr. Mahesh Babu, Dr. Vijay Anand and Dr. Sriram Thanigai}

DOI: http://dx.doi.org/10.22271/ortho.2017.v3.i2i.86

\section{Abstract}

Introduction: The malrotation of calcaneum and talus is the aetiology behind resistant clubfeet. The surgical release procedures are aimed at realignment of these pathological structures with minimal scarring and wound problems. Carroll's technique uses 2 incisions to achieve this goal.

Materials and Methods: A prospective study of twenty severe and resistant club feet of children aged 6 months to 18 months operated using a modified Carroll technique was done. All patients were followed up for atleast 36 months. They were assessed clinically by Dimeglio score and radiological angles namely mean talocalcaneal index, anteroposterior talocalcaneal angle and lateral talocalcaneal angle.

Results: 8 severe clubfeet had improved to grade 1 . In the remaining 12 very severe clubfeet improved to grade 1 in 9 patients and grade 2 in 3 patients based on Dimeglio method. There was significant improvement in radiological parameters as well.

Conclusion: We found that this incision gives better exposure of the pathoanatomy of the clubfoot especially the posteromedial and posterolateral ligament complex with easy skin closure.

Keywords: Club feet, modified Carroll technique

\section{Introduction}

The clubfoot is the most common congenital orthopaedic condition requiring intensive treatment. As the clubfoot most likely represents a congenital dysplasia, treatment of idiopathic true clubfoot can never produce a normal extremity.

Herzenberg with his three dimensional computer modeling found that the body of the talus is rotated externally while the neck is rotated internally in a clubfoot. Fuller emphasized the tethering effect of posterolateral structures which prevent dorsiflexion of the ankle joint and stressed the importance of releasing the calcaneofibular and posterior talofibular ligaments. Mckay described the abnormal rotation of the calcaneus under the talus in sagittal, coronal and horizontal planes.

The basic objectives of treatment of clubfoot are

i) To correct abnormal tarsal relation.

ii) To maintain the reduction

iii) To establish muscle balance between evertors and invertors, dorsiflexors and plantar flexors.

iv) To provide mobile foot with normal function and weight bearing

Initial treatment of CTEV, is always by nonoperative means of corrective manipulation, strapping, serial cast application and splinting. Ponseti's technique has revolutionized the treatment of clubfoot. As it necessitates proper follow-up of patients, in a rural setting it has its practical difficulties. Maintaining the plaster properly in a hot and humid environment by parents in this background is tedious and they expect a treatment with shortest possible hospital visits.

The rationale for soft tissue release is that realignment of the talus, calcaneum and navicular allows remodelling of the articular surfaces to occur. A variety of surgical procedures and techniques have been described to achieve the goal of complete anatomic restoration. The first description of a radical approach was published by. The one stage posteromedial release described by Turco (1971) ${ }^{[19]}$ has been the standard procedure in many centres. Complete subtalar release was described by.

\section{Dr. Vijay Anand}

MBBS MS (Ortho), Associate Professor, SRM Medical College, SRM Nagar, Potheri,

Kattankulathur, Kancheepuram District, Near Potheri Railway Station, Chennai, Tamil Nadu, India 
Wound complications like skin slough, dehiscence, infection and incomplete correction have been reported with Turco procedure and Cincinnati's circumferential approach. This results in hypertrophic scar and deformity recurrence.

Carroll (1987) ${ }^{[2]}$ used two separate incisions, a curvilinear medial and a posterolateral incision to allow adequate exposure for lateral, posterior, plantar and medial release. The current study used a simpler 2 incisions technique and assesses the radiological and functional outcomes in idiopathic CTEV.

\section{Materials and Methods}

A prospective study was done in Chengelpet medical college hospital with 20 severe resistant clubfeet of 17 children. The study was done from November 2011 to January 2014. The children included in the study were

a. Age of the child between 4 months and 2 years

b. Resistant clubfoot - failure of achieve correction with plaster methods

c. Severe and very severe clubfoot

The children excluded from the study were

1. Relapsed clubfoot

2. Recurrent clubfoot

3. Neglected clubfoot

4. Teratologic clubfoot, i.e., clubfoot secondary to neuromuscular causes like cerebral palsy and Arthrogryposis multiplex congenita.

Ethical committee clearance was obtained from the institution. We used Dimeglio method of grading severity of clubfoot. Each major component of clubfoot (ankle equinus, heel varus, derotation of calcaneopedal block and forefoot adductus) is graded clinically from 4 to 1 (most severe to mild). Additional points are added for deep posterior and medial creases, cavus and poor muscle function. Total score is stratified into four groups of severity (Benign to very severe, Grade I to IV).

All the cases had preoperative and postoperative radiographs to assess degree of deformity. Radiographic assessment consisted of anteroposterior talocalcaneal angle, lateral talocalcaneal angle and talocalcaneal index. Statistical analysis was done using student $\mathrm{t}$ test.

\section{Surgical Technique}

\section{Anaesthesia and position}

Under general anaesthesia in a semilateral position, we operated all our cases. Tourniquets were used throughout the surgery to ensure a bloodless operating field.

\section{Curvilinear Medial Incision}

The landmarks for the medial incision are the centre of the os calcis, the front of the medial malleolus and the base of the first metatarsal. These three points define a triangle. The incision is parallel with the base of the triangle but curved in the plantar direction proximally and over the dorsum of the foot distally.

Posterolateral incision: Runs obliquely from the midline of the distal calf posteriorly to a point midway between the tendocalcaneus and the lateral malleolus.

\section{Procedure}

Through the posterolateral incision, the sural nerve and short saphenous vein were identified and protected. Lengthening of tendocalcaneus was done by a sagittal ' $Z$ ' plasty technique detaching the medial half of the tendon from the calcaneus. The deep fascia overlying the flexor hallucis longus and neurovascular bundle is opened. Tibialis posterior was identified and lengthened. The posterior and lateral capsule of ankle and subtalar joint was opened. The tight posterior calcaneofibular and posterior talofibular ligaments were divided. The posterior portion of the deltoid ligament was divided.

Through the medial incision, the abductor hallucis was freed from the oscalcis. The plantar fascia was incised and Henry's knot was sectioned. The flexor hallucis longus and flexor digitorum longus together with the neurovascular bundles were retracted in the plantar direction. The long and short plantar ligaments were divided. Calcaneonavicular ligament was divided. Capsulotomy of the talonavicular joint and calcaneocuboid joint were done. With the foot in a plantigrade position, we verified correction obtained. In needed cases, intramuscular recession of flexor hallucis longus and flexor digitorum longus tendon were done. With the foot held in plantigrade position, the tendocalcaneus and tibialis posterior were repaired. Wound closed and compressive dressing applied. Above knee slab applied. We did not use ' $\mathrm{K}$ ' wire to stabilize the joint.

\section{Postoperative Protocol}

Under anaesthesia on $14^{\text {th }}$ postoperative day, we removed the sutures and applied long leg cast with knee in $70^{\circ}$ flexion and ankle and foot in neutral position. On subsequent follow-up, we applied Plaster of Paris cast for 12 weeks postoperative period. The cast was changed every 2 weeks. We applied orthosis subsequently till the child started walking. Later clubfoot boot was given to maintain correction. Postoperative radiographs were taken to assess radiological correction.

From the original Carroll double incision technique, we adopted the following modifications. We operated all the cases in semi lateral position. We did not use ' $\mathrm{K}$ ' wire to stabilize the joint. We applied plaster of paris slab with knee in flexion in the immediate postoperative period.

\section{Results}

The age group varied from a minimum of 5 months to a maximum of 18 months and average age was 8 months. The maximum follow up was 60 months. Average follow up was 24 months. Of the 17 children, right side was involved in 5 cases and left side was involved in 9 cases; 3 cases were bilateral. Of 20 clubfeet, 8 were of grade III severity and 12 were of grade IV severity. The entire wound healed primarily without infection and breakdown.

Residual deformities were present in 3 cases. One child had residual forefoot adduction and supination. Two other children had residual forefoot adduction deformity. Residual deformities in all the three children were moldable and we are treating these children with corrective cast itself.

Of 12 very severe club feet, 9 feet improved to benign grade and 3 feet improved to moderate grade. All the 8 severe club feet, improved to benign grade after surgery. Good results were achieved in 17 of the 20 clubfeet $(85 \%)$ based on DiMeglio method.

The postoperative mean talocalcaneal index achieved was $42.9^{\circ}$ (Normal range $>40^{\circ}$ ). The postoperative mean anteroposterior talo-calcaneal angle was $25.5^{\circ}$ (Normal range $30^{\circ}$ to $55^{\circ}$ ). The Postoperative mean lateral talo-calcaneal angle was $17.4^{\circ}$ (Normal $20^{\circ}$ to $40^{\circ}$ ). 
Table 1: Preoperative Grading Of Severity

\begin{tabular}{|c|c|c|}
\hline Dimeglio Grade & No. of Clubfeet & Percentage \\
\hline Grade III & 8 & $40 \%$ \\
\hline Grade IV & 12 & $60 \%$ \\
\hline
\end{tabular}

Table 2: Dimeglio Method

\begin{tabular}{|c|c|c|}
\hline Grade & Type & Points \\
\hline I & Benign & $<5$ \\
\hline II & Moderate & $=5<10$ \\
\hline III & Severe & $=10<15$ \\
\hline IV & Very severe & $=15<20$ \\
\hline
\end{tabular}

\begin{tabular}{|c|c|c|c|}
\hline Reducibility & Points & Other Parameters & Points \\
\hline $90^{\circ}-45^{\circ}$ & 4 & Posterior crease & 1 \\
\hline $45^{\circ}-20^{\circ}$ & 3 & Medial crease & 1 \\
\hline $20^{\circ}-0^{\circ}$ & 2 & Cavus & 1 \\
\hline$<0^{\circ}-20^{\circ}$ & 1 & Poor muscle function & 1 \\
\hline
\end{tabular}

Table 3: Postoperative Grade

\begin{tabular}{|c|c|c|}
\hline Dimeglio Grade & No. of club feet & Percentage \\
\hline Grade I & 17 & $85 \%$ \\
\hline Grade II & 3 & $15 \%$ \\
\hline
\end{tabular}

Table 4: Results

\begin{tabular}{|c|c|c|}
\hline Preoperative Grade & No. of club feet & Post- operative Grade \\
\hline $\begin{array}{c}\text { IV } \\
\text { (Very severe) }\end{array}$ & $12 \overleftrightarrow{\longrightarrow 9} \begin{array}{c}\text { I (Benign) } \\
\text { II (Moderate) }\end{array}$ \\
\hline III (Severe) & $8 \longrightarrow 3$ & I (Benign) \\
\hline
\end{tabular}

Table 5: Radiological Evaluation

\begin{tabular}{|c|c|c|c|}
\hline Angle/index & Preoperative value & Postoperative value & Mean change \\
\hline Antero posterior Talocalcaneal Angle & $13.4 \pm 4.35$ & $25.5 \pm 3.17$ & 12.1 \\
\hline Lateral Talocalcaneal Angle & $6 \pm 2.42$ & $17.4 \pm 4.11$ & 11.4 \\
\hline Talocalcaneal Index & $19.4 \pm 4.86$ & $42.9 \pm 4.56$ & 23.5 \\
\hline
\end{tabular}

\begin{tabular}{|c|c|c|c|}
\hline Study & No. of club feet & Results & Follow up \\
\hline Yoneda and Carroll & 84 & $82 \%$ good results & 5 years \\
\hline Hee, Hwan-Tak, Lee & 58 & $85 \%$ good results & 5.5 years \\
\hline Porat & 33 & $82 \%$ good results & 5 years \\
\hline
\end{tabular}
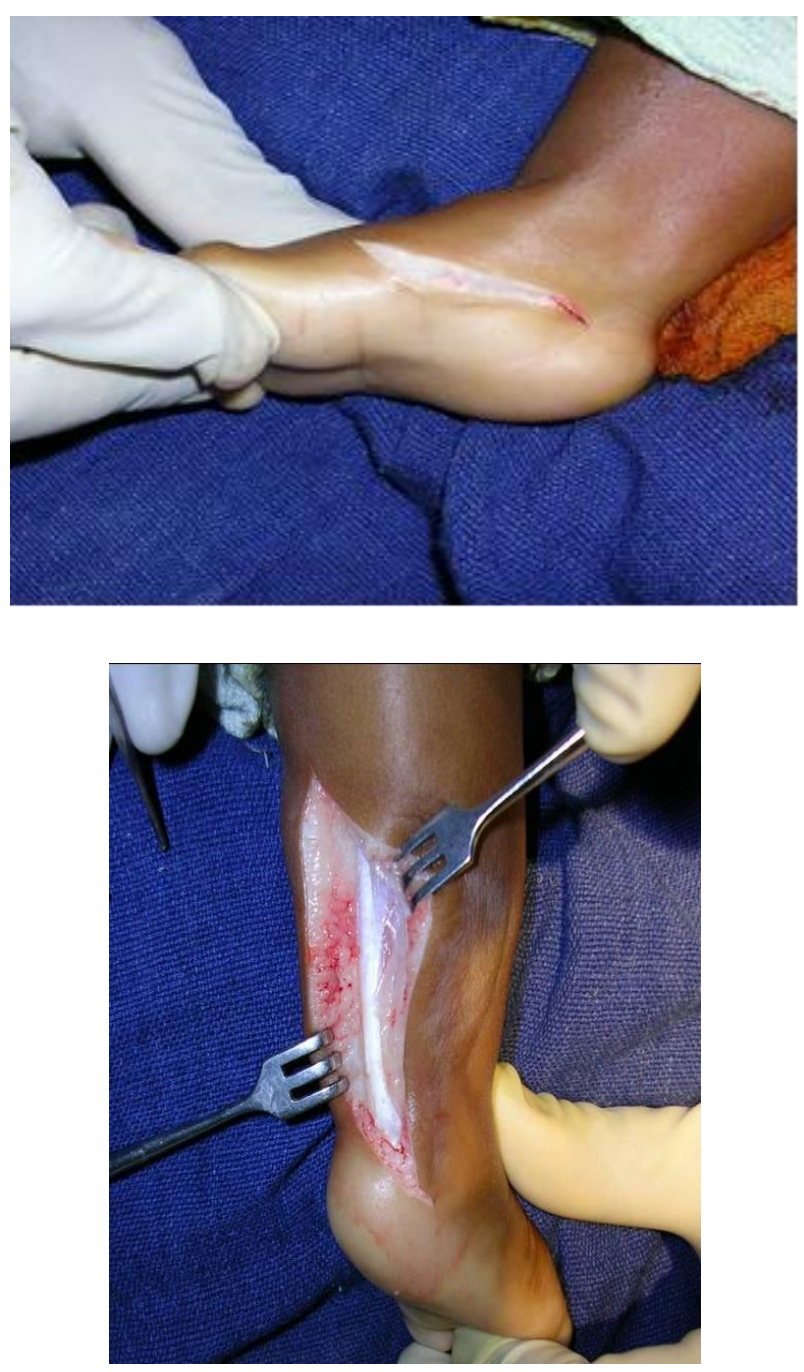
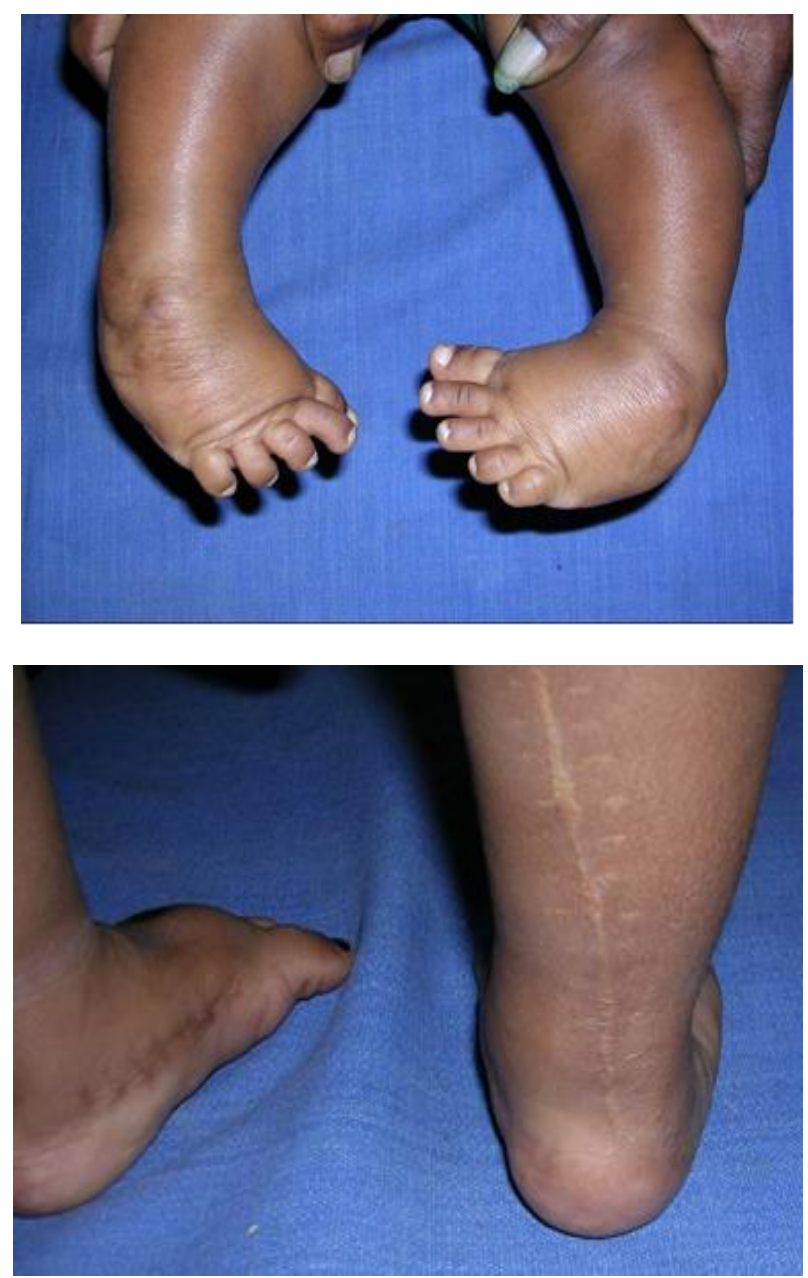


\section{Discussion}

The goal of treatment of clubfoot is to obtain a painless, plantigrade, pliable, normal looking foot with good function.

Codivilla in 1906 first described a radical approach in treating clubfoot. Brockman described his extensive soft tissue release (in 2 stages) in 1930. The importance of early surgical release was emphasized by Attenborough in 1960. Turco described his one stage posteromedial release in 1971. The Cincinnati incision was later described by Crawford et al ${ }^{[3]}$. to allow complete subtalar release.

Long curved posteromedial incision affect wound healing. Hypertrophic and contracted scar may result. Scar itself acts as deforming force, producing residual deformity and stiffness. Release of calcaneocuboid joint and release of posterolateral tether are difficult. Exposure of plantar fascia is also difficult.

Circumferential Cincinnati incision does not allow as complete a posterior release as Carroll's approach would allow, especially in severe resistant cases. In Cincinnati incision, heel flap vascularity is also at risk.

Carroll's approach provides good exposure of the entire pathological anatomy without compromising wound healing. Especially in severe cases, the posterolateral tether is the main causative factor for equinus deformity. Carroll's approach allows good access to the posterolateral tether.

Porat et al, Depuy and Drennan, Franke and Hein proposed that the best results are obtained with early operation i.e., between fourth and sixth months of life. In this series, the average age of patients was 8 months.

Otremski et al found that forefoot correction was inadequate in the Turco procedure unless plantar release was added to the procedure and the fact that the tibialis posterior tendon is removed, may be a source of secondary valgus deformity in some patients.

Yngve et al whose procedure involve, club foot release without wide subtalar release, reported that 82 percent of their surgeries resulted in a satisfactory functional rating. Manzone et al reported no significant differences in functional results in clubfoot treated with posteromedial release and complete extensive release.

Yamamoto and Furuya, Thompson et al reported good correction and function in $75 \%$ to $85 \%$ of cases with Turco's procedure. Howard and Diaz reported $87 \%$ satisfactory results with posteromedial and lateral release. Their results improved in ensuring that calcaneocuboid joint was properly reduced.

Carroll et al reviewed their results and found that $81 \%$ of the patients had a satisfactory result. Bensahel believed that the extent of the surgery should be matched to the complexity of the club foot deformity - "a la carte" approach. Yoneda and Carroll ${ }^{[18]}$ reviewed the results of surgical correction of 84 severe clubfeet by Carroll's double incision technique at 5 years follow up. They achieved good results in $82 \%$ cases.

Porat $^{14}$ reviewed 33 severe clubfeet treated by Carroll's double incision technique after an average of 5 years follow up. $82 \%$ cases had satisfactory results.

Hee, Hwan - Tak, Lee ${ }^{7}$ reviewed 58 severe clubfeet treated surgically using Carroll's approach after an average follow up of 5.5 years. $85 \%$ cases had good results.

David Roye and Benjamin Roye ${ }^{[4]}$ in their study compared long tem results of the Carroll procedure with those of limited posterior release. They found that patients undergoing the Carroll procedure had significantly fewer surgeries and less stiffness.

Haesbeck and Wright ${ }^{[6]}$ found that on an average of 28 years after surgery, patients who had comprehensive release had fewer operations, more complete correction of heel varus and improved subtalar motion when compared to those with isolated posteromedial release.

In our series, we achieved good results in $85 \%$ cases. We did not encounter wound healing problems. All wounds healed primarily without infection and breakdown. In this study, three children had residual deformities. Forefoot adduction was present in all the three children and in addition, one child had supination of the forefoot. In our short term follow up, we have obtained morphologically normal looking and supple foot in all the cases. We need longer term follow up to assess functional outcome, gait pattern, size of foot, pain, mobility of ankle and subtalar joint. The main limitations of our study are less number of cases in the study and relatively shorter period of follow up.

To conclude, Carroll's dual incision technique offers goods exposure to the posterolateral, subtalar and medial structures without wound healing problems. This technique gives supple and cosmetic foot. With our limited experience in this technique, it is definitely a procedure of choice in the surgical management of severe resistant club foot.

\section{Reference}

1. Carroll NC, McMurty R, Leete SF. The Pathoanatomy of Congenital Clubfoot. Orthop Clin North Am 1978; 9:225.

2. Carroll NC: Congenital Club foot: Pathoanatomy and treatment, Instr Course Lect 1987; 36:117.

3. Crawford AH, Marxen JL, Osterfeld DL: the Cincinnati incision: a Comprehensive approach for surgical procedures of the foot and ankle in childhood, J Bone Joint Surg. 1982, 64:1355.

4. David P, Roye, Benjamin D, Roye: Long term results of Carroll's approach: J Am Acad Orthop Surg, 2002; 10:239-248.

5. Dimeglio A, Bensahel H, Souschet $\mathrm{P}$, et al. Classification of clubfoot. J Pediatr Orthop B. 1995; 4:129.

6. Green ADL, Lloyd Roberts GC, Results of earlier posterior release in resistant clubfoot. J Bone Joint Surg $1985 ; 67: 593$.

7. Haasbeck JF, Wright JG: A comparison of the long term results of posterior and comprehensive release in the treatment of clubfoot, J Pediatr Orthop 17:29, 1997.

8. Hee, Hwan-Tak, Lee, Eng-Hin: Surgical results of clubfoot using Carroll's approach: Journal of Orthopaedic Surgery: Dec 1997.

9. Herzenberg J, Carroll NC, Christofersen MR, Lee EH, White S, Munroe R et al. Clubfoot Analysis with Threedimensional Computer Modeling. J. Ped. Orthop. 1988; 8:257-262.

10. Ippolito E, Ponseti IV: Congenital Clubfoot in human fetus: a histological study, J Bone Joint Surg. 1980, 62:8.

11. Irani R, Sherman MS. the pathological anatomy of clubfoot. J Bone Joint Surg. 1963, 45:45.

12. Kite JH: Non operative treatment of congenital clubfoot. Clin Orthop 84: 29-38, 1972; 22:1015-6.

13. Mckay DW. New Concept and approach to clubfoot treatment; Section I-Principles and Morbid Anatomy J.Ped, Orthop, 1980-2:347.

14. Mckay DW. New concept and Approach to clubfoot treatment; Section II- Correction of the Clubfoot. 1983, 3:10.

15. Ponseti. Treatment of Congenital clubfoot, J Bone Joint Surg. 1992; 74:448.

16. Porat S, Kaplan L: Critical Analysis of results in clubfeet treated surgically along the Norris Carroll approach; J 
Pediatr Orthop. 1989; 9:137-43.

17. Simons GW: Complete subtalar release in clubfoot. Part II. Comparison with less extensive procedures. J Bone Joint Surg. 1985, 67:1056.

18. Simons GW, A standardized Method for the Radiographic Evaluation of clubfeet; Clin Orthop, 1978; 135:107-118.

19. Turco VJ: Surgical correction of the Resistant clubfoot. One stage Posteromedial release with internal fixation. J Bone Joint Surg. [AM] 1971; 53:477-97.

20. Yoneda B, Carroll NC: One stage surgical management of Resistant Clubfoot: J Bone Joint Surg (B) 1984, 66:30. 